\title{
STRUCTURAL PROPERTIES OF PZT THIN FILMS: THE EFFECTS OF HEAT TREATMENT
}

\author{
Lima, E. C. ${ }^{1}{ }^{*} ;$ Araújo, E. B. ${ }^{2}$ \\ ${ }^{1}$ Universidade Federal do Tocantins, Porto Nacional,Tocantins, Brazil \\ ${ }^{2}$ Departamento de Física e Química, UNESP - Universidade Estadual Paulista,Ilha Solteira, São Paulo,Brazil. \\ *eltonlima@uft.edu.br
}

\begin{abstract}
The effects of heat-treatment conditions on crystallographic orientation and phase transformations were studied on lead zirconate titanate $\mathrm{Pb}\left(\mathrm{Zr}_{0.50} \mathrm{Ti}_{0.50}\right) \mathrm{O}_{3}$ (PZT) thin films. Films deposited on platinum with a chemical solution can exhibit 111 or 100 texture, however, there is no consensus about the mechanisms responsible for texture during heat treatment processes. The heat treatment affects directly the densification of the film as well as the residual stress developed. In addition, the formation of impurities as a pyrochlore phase $\left(\mathrm{Pb}_{2}\left(\mathrm{Zr}_{1-\mathrm{x}} \mathrm{Ti}_{\mathrm{x}}\right)_{2} \mathrm{O}_{6}\right)$ was noticed by several authors. In this work, the evolution of phases and trends of texture were characterized for different temperatures of pyrolysis in PZT thin films using X-ray diffraction. The perovskite phase coexists with the pyLicearochlore phase to the film pyrolyzed from $350^{\circ} \mathrm{C}$ to $450^{\circ} \mathrm{C}$. However, the films produced at low temperature pyrolysis showed only the presence of the perovskite phase. The Rietveld method was used to quantify the percentage of each phase as a function of temperature of pyrolysis. The microstrain and the residual stress was evaluated to explain the mechanisms responsible for texture and phase transformations in PZT films.
\end{abstract}

